Research Article

\title{
Mechanical Properties and Strength Grading of Engineered Bamboo Composites in China
}

\author{
Siyuan Tang $\mathbb{D},{ }^{1,2}$ Aiping Zhou $\mathbb{D}^{1},{ }^{1}$ and Jiannan $\mathrm{Li}^{3}$ \\ ${ }^{1}$ National Engineering Research Center of Biomaterials, Nanjing Forestry University, Nanjing, China \\ ${ }^{2}$ School of Architecture and Transportation Engineering, Guilin University of Electronic Technology, Guilin, China \\ ${ }^{3}$ School of Civil Engineering, Changzhou Institute of Technology, Changzhou, China \\ Correspondence should be addressed to Siyuan Tang; 404533342@163.com
}

Received 24 December 2020; Revised 1 March 2021; Accepted 29 March 2021; Published 22 April 2021

Academic Editor: Giosuè Boscato

Copyright ( $\odot 2021$ Siyuan Tang et al. This is an open access article distributed under the Creative Commons Attribution License, which permits unrestricted use, distribution, and reproduction in any medium, provided the original work is properly cited.

Engineered bamboo composite (EBC) is a new high-strength anisotropic structural material, which has standardized sections and less inherent variability than the natural material. For safety reasons in structural applications, the characteristic values of mechanical behaviors are needed to build the design values utilized in practical application. Recent research studies on EBC focused on the mechanical properties from a single source, with little research on the sampling of the manufacturers. The present work investigates mechanical properties of two types of commercially available EBC-parallel strand bamboo (PSB) and laminated veneer bamboo (LVB). The main aim of this work is to evaluate the best probability distribution model (normal, lognormal, and Weibull) and mechanical properties for EBC in China and determine the characteristic values indicated by ASTM D2915. The mechanical properties in tensile, compression, and shear were evaluated using about 4300 small clear specimens from seven manufacturers in five raw bamboo origins of China. Based on the confidence band method, the strength grading of EBC subjected to compressive strength was developed with two predictors (density and MOE). By using intervals of each predictor, several strength grades were built. Each grade has the mean compressive strength, 5th percentile lower value $\left(R_{0.05}\right)$, and characteristic value $\left(R_{k}\right)$, which could be used in structural design. This research contributes to the establishment of EBC standards and is essential for further accepting these materials in structural engineering.

\section{Introduction}

Bamboo is a sustainable and natural material. It is a crucial forest resource other than timber. Therefore, bamboo has been used as a building material for thousands of years. Due to bamboo's circular hollow section and range of available sizes, the scope of possible structural applications for natural round culms is limited. Instead, EBCs have become more popular in academic and engineering application fields. In recent years, several forms of engineered bamboo composite have been rapidly developed and applied [1]. Figure 1 shows some examples of EBC structure.

China presents an enormous potential for EBC applications since Moso bamboo (the primary raw material of EBC) resources are widespread in natural forests and are cultivated over large areas in Mainland China, including
Hunan, Jiangxi, Hubei, Zhejiang, Fujian, and Anhui Provinces (see Figure 2). The EBCs are bamboo-based composites designed for structural applications with specific mechanical properties, including parallel strand bamboo (PSB) and laminated veneer bamboo (LVB). The PSB is a composite of bamboo strand elements with bamboo fibers primarily orientated along the member's longitudinal axis (see Figure 3 ). LVB is also a composite of bamboo strand elements, edge-bonded to form veneer sheets of uniform sectional dimensions, which are then face-bonded to develop finished products, with bamboo fibers primarily oriented along the longitudinal axis of the member (see Figure 3).

The EBC shows the anisotropic behavior typical of natural bamboo, comparable to that of fiber reinforced composites $[3,4]$. A significant number of experiments 


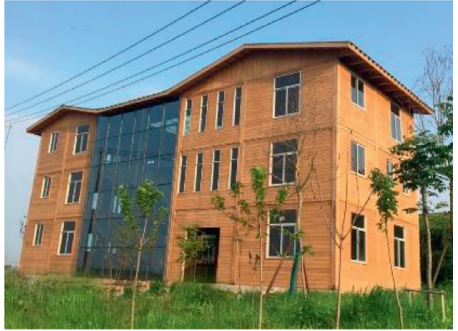

(a)

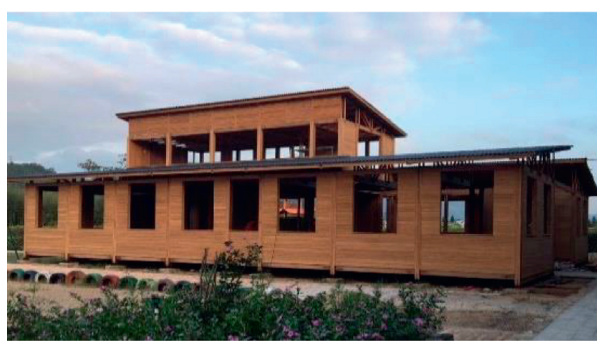

(b)

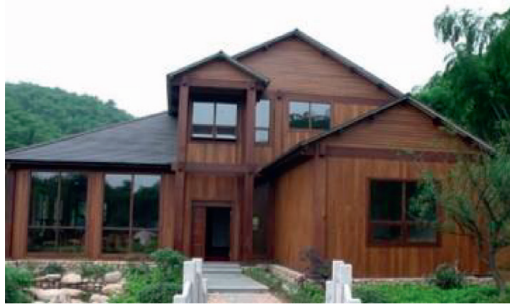

(c)

Figure 1: Examples of EBC structure.

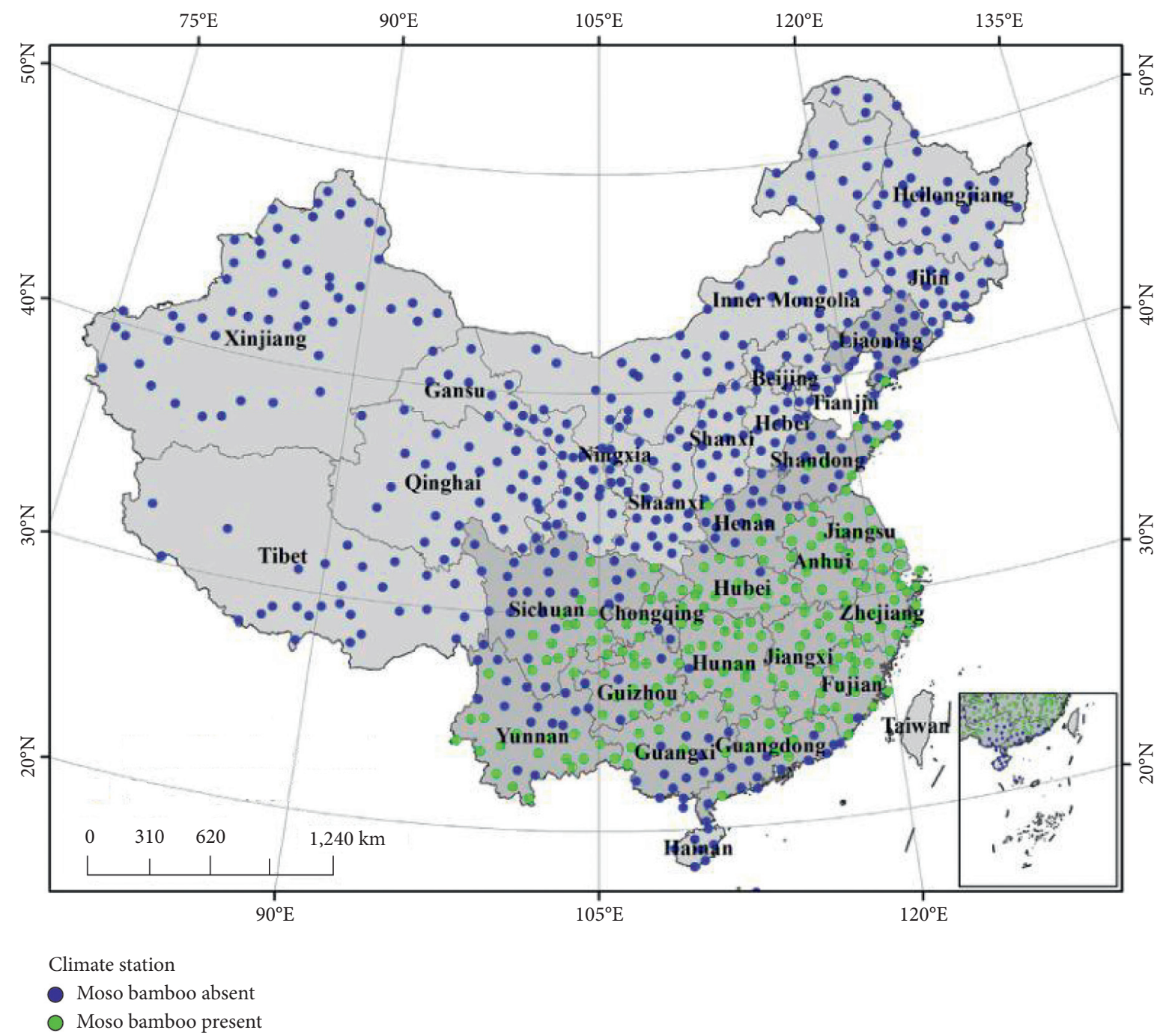

Figure 2: The information on the distribution of Moso bamboo in Mainland China by Shi [2].

have been conducted to investigate the mechanical properties of bamboo composites. Huang $[5,6]$ studied the mechanical properties of PSB by experiments and investigated stress-strain relationships and failure mechanisms in each stress state. Wei [7] provided a comprehensive research on the mechanical behavior and failure modes of bamboo scrimber (PSB) and laminated bamboo (LVB) and proposed the stress-strain models for EBC. Xiao $[1,8]$ studied the mechanical properties of glubam boards and found that the Weibull distribution and normal distribution are best fit for shear strength and the in-plane shear strength, respectively, and suggested the characteristic values and the design values. Sharma et al. [9] provided a comprehensive study that compares bamboo scrimber, 


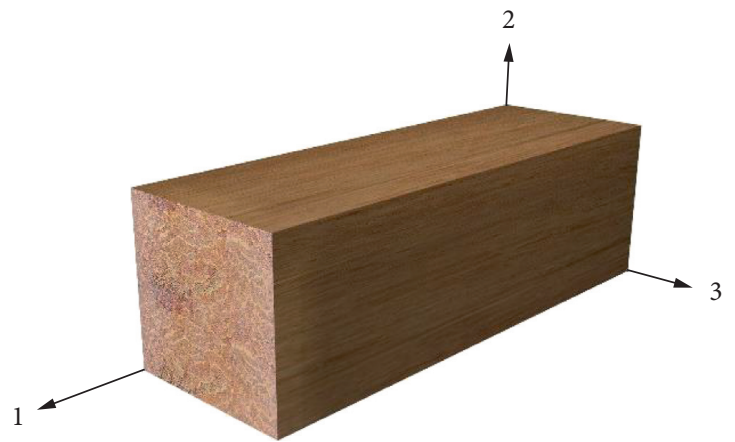

(a)

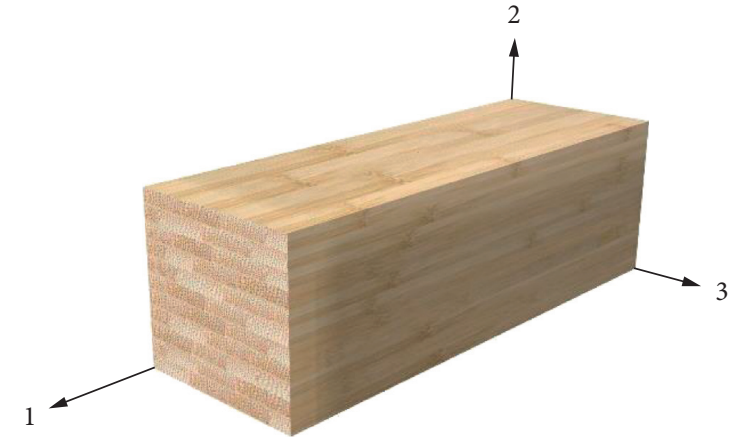

(b)

FIgURE 3: Engineered bamboo composites: parallel strand bamboo (a); laminated veneer bamboo (b).

laminated bamboo, timber, and engineered timber products for mechanical properties. Kumar et al. [10] studied the influence of bamboo scrimber densities on the mechanical properties and concluded that the density has significant influence on the mechanical properties of bamboo scrimber. There is no sampling and statistical research on the physical and mechanical properties of EBC products from different manufacturers, which makes the formulation of standards lack data reference.

The characteristic value is the representative value of a material property used for design. The standards $[11,12]$ define the 5 th percentile value at the $75 \%$ confidence level for structural materials as characteristic value of strength, and the determination method includes nonparametric and parametric. The parametric approach calculates the characteristic value of strengths according to the estimated statistical average and standard deviation of the sample. The nonparametric approach is to sort the sample data from small to large to determine the strength corresponding to the data point as the characteristic value of strength. Therefore, it is vital to determine the characteristic values of mechanical property of EBC for engineering applications, and it is also the basis for determining its strength design value in the future.

EBC for structural applications has to be strength graded before its use. For economic reasons, the most important physical and mechanical properties (e.g., density, modulus, and strength) are the basic grading principles. For bamboo culm, Trujillo et al. [13] indicated that grading could be utilized based on physical properties and flexural stiffness. Nurmadina et al. [14] and Bahtiar [15, 16] studied several potentials, including $M c$, density, and linear mass, for bamboo culm both in flexural and compressive strength grading. The grading of timber and bamboo are constantly studied, but the strength grading of EBC subject to compressive properties is still missed.

In order to build the $\mathrm{EBC}$ standards and contribute to the use of EBC for structural purposes, this research aimed to determine the probability distribution and the characteristic value of the mechanical properties for EBC by tests. Afterward, the Indicating Properties (IPs) which were the best for predicting compressive strength of EBC were determined. The strength grading was developed by the confidence band method for EBC based on compressive properties. It will provide more design-relevant data for engineering applications.

\section{Materials and Methods}

2.1. Materials. In order to objectively reflect the mechanical properties of EBC in China, this study randomly took EBC products from seven manufacturers with raw materials from five primary bamboo origins. Different types of EBC from manufacturers were divided into nine groups. All of the EBC products were manufactured of Moso bamboo (Phyllostachys pubescens), and the material information is shown in Table 1. Each group of materials required the same batch of products from the same manufacturer. Test specimens were processed to the specified dimensions (Table 2) and transported to the laboratory.

2.2. Sample Size. The population is characterized by the sample, therefore enough sample size must be adopted. In this study, the sample size is obtained based on ASTM D2915 [13]. On the $95 \%$ confidence level, the required minimum sample size $n$ of specimens is

$$
n=\left(\frac{t s}{\alpha \bar{X}}\right)=\left(\frac{t}{\alpha} \mathrm{CV}\right)^{2}
$$

where $s$ is the standard deviation of specimen values; $\bar{X}$ is the specimen mean value; $\mathrm{CV}$ is the coefficient of variation (it was assumed first as 0.1 for physical properties and 0.2 for mechanical properties); $\alpha$ is the estimate of precision, taken as 0.05 ; and $t$ is the value of the $t$ statistic, taken as 2.093 (physical properties) and 2 (mechanical properties) for 0.95 confidence level. The minimum number of specimens is 18 (physical properties) and 64 (mechanical properties) for each test based on the testing standard. To ensure an adequate test sample size, the number of specimens for physical properties and mechanical properties is 80 .

2.3. Testing Methods. The mechanical properties of testing included tensile, compressive, and shear tests in both directions to the grain. The same method of testing was used for both PSB and LVB. The dimensions were measured 
TABLE 1: The raw material information of engineered bamboo composites.

\begin{tabular}{|c|c|c|c|c|c|}
\hline Group & Material & $\begin{array}{l}\text { Origin of raw } \\
\text { bamboo }\end{array}$ & $\begin{array}{l}\text { Age of raw } \\
\text { bamboo }\end{array}$ & Resin types & Manufacturer \\
\hline EBC1 & PSB & Jiangxi Province & 4 years & Urea formaldehyde resin & Jiangxi Feiyu Bamboo Co., LTD \\
\hline EBC2 & PSB & Hunan Province & 5 years & $\begin{array}{l}\text { Phenol formaldehyde } \\
\text { resin }\end{array}$ & $\begin{array}{c}\text { Hunan Taohuajiang Bamboo Technology Co., } \\
\text { LTD }\end{array}$ \\
\hline EBC3 & PSB & Fujian Province & 5 years & $\begin{array}{l}\text { Phenol formaldehyde } \\
\text { resin }\end{array}$ & Fujiang Jinzhu Bamboo Co., LTD \\
\hline EBC4 & PSB & Zhejiang Province & $3-5$ years & $\begin{array}{l}\text { Phenol formaldehyde } \\
\text { resin }\end{array}$ & Guangyu Bamboo Industry Co., LTD \\
\hline EBC5 & PSB & Anhui Province & $3-6$ years & $\begin{array}{l}\text { Phenol formaldehyde } \\
\text { resin }\end{array}$ & Anhui Hongyu Bamboo Technology Co., LTD \\
\hline EBC6 & LVB & Jiangxi Province & 5 years & Urea formaldehyde resin & Jiangxi Feiyu Bamboo Co., LTD \\
\hline EBC7 & LVB & Hunan Province & 5 years & $\begin{array}{l}\text { Phenol formaldehyde } \\
\text { resin }\end{array}$ & $\begin{array}{c}\text { Hunan Taohuajiang Bamboo Technology Co., } \\
\text { LTD }\end{array}$ \\
\hline EBC8 & LVB & Fujian Province & $3-5$ years & $\begin{array}{l}\text { Phenol formaldehyde } \\
\text { resin }\end{array}$ & Shaowu Xingda Bamboo Co., LTD \\
\hline EBC9 & LVB & Zhejiang Province & 5 years & $\begin{array}{l}\text { Phenol formaldehyde } \\
\text { resin }\end{array}$ & Zhejiang Shanglin Bamboo Co., LTD \\
\hline
\end{tabular}

thrice for each specimen. All parameters of dimension were measured using a vernier caliper with an accuracy of $0.001 \mathrm{~mm}$. The EBC specimens were conditioned in a chamber at $65 \%( \pm 5 \%)$ relative humidity and $20^{\circ} \mathrm{C}\left( \pm 2^{\circ} \mathrm{C}\right)$ temperature prior to testing for one month.

Since the EBC is a new composite and no test standard has been established, the standards for timber structure and composite materials are referenced in studying the mechanical properties of EBC. For each group, density and moisture content were determined based on the specimens of compression in parallel to grain according to GB/T 1933 [17]: Method for determination of the density of wood and GB/T 1931 (air-dry method) [18], respectively. The tests of tensile and compressive were conducted following ASTM D143 [19]: Standard test methods for small clear specimens of timber. The tests of shear were in accordance with principles of ASTM D7078 [20]: Standard test method for shear properties of composite materials by $\mathrm{V}$-notched rail shear method. The mechanical properties were measured with a universal testing machine using load cell of $100 \mathrm{kN}$ capacity. Two strain gauges were affixed to the surface in the middle of the specimen to measure the strains along with two directions, namely, parallel and perpendicular to grain directions, respectively. The data logger (TML TDS-640) automatically recorded the load and the strains during the tests. The standards, test methods, number of specimens, and test parameters used are summarized in Table 2.

2.4. Data Analysis. Statistical distributions were fitted to the experimental data obtained by the maximum likelihood estimates method. The Kolmogorov-Smirnov [21] test was used to verify the goodness of fit analysis. Both methods were using the software MATLAB ${ }^{\circledR}$ version R2018b. In this study, the probability distributions were fitted with normal, lognormal, and Weibull models. The general equations for probability density functions and cumulative distribution functions are calculated using equations (2)-(7):

$$
\begin{aligned}
x-N(\mu, \sigma): f(x) & =\frac{1}{\sqrt{2 \pi} \sigma} e^{-(x-\mu)^{2} / 2 \sigma^{2}}, \\
F(x) & =\Phi\left(\frac{x-\mu}{\sigma}\right), \\
x-L\left(\mu_{\ln }, \sigma_{\ln }^{2}\right): f(x) & =\frac{1}{\sqrt{2 \pi} \sigma_{\ln } x} e^{-\left(\ln x-\mu_{\ln }\right)^{2} / 2 \sigma_{\ln }^{2}}, \\
F(x) & =\Phi\left(\frac{\ln x-\mu_{\ln }}{\sigma_{\ln }}\right), \\
x-W(k, \lambda): f(x) & =\frac{k}{\lambda}\left(\frac{x}{\lambda}\right)^{k-1} e^{-(x / \lambda)^{k}}, \\
F(x) & =1-e^{-(x / \lambda)^{k}},
\end{aligned}
$$

where $x$ is the strength; $\mu$ is the mean value of the distribution; $\sigma$ is the standard deviation; $\mu_{\ln }$ is the mean value of logarithmic; $\sigma_{\ln }$ is the standard deviation value of logarithmic; $k$ is the shape parameter; and $\lambda$ is the scale parameter.

In this study, the mean value of the best-fit distribution is used for the characteristic value of moduli. The 5th percentile value with $75 \%$ confidence level from test results shall be the characteristic value for strengths. According to the ASTM D2915, the characteristic value of strength corresponding to the 5 th percentile value with $75 \%$ confidence level for the normal, lognormal, and Weibull distribution of the strengths can be calculated as follows:

$$
\begin{aligned}
& f_{k, 0.05}=\mu-K_{N} \sigma, \\
& f_{k, 0.05}=\mu_{\text {In }}-K_{\text {In }} \sigma_{\text {In }}, \\
& f_{k, 0.05}=\bar{X}-K_{W} S,
\end{aligned}
$$

where $\mu$ is the mean of the normal distribution; $\sigma$ is the standard deviation of the normal distribution; $K_{N}$ is the confidence level factor of the normal distribution; $\mu_{\text {In }}$ is the 
TABLe 2: Experimental methods for EBC.

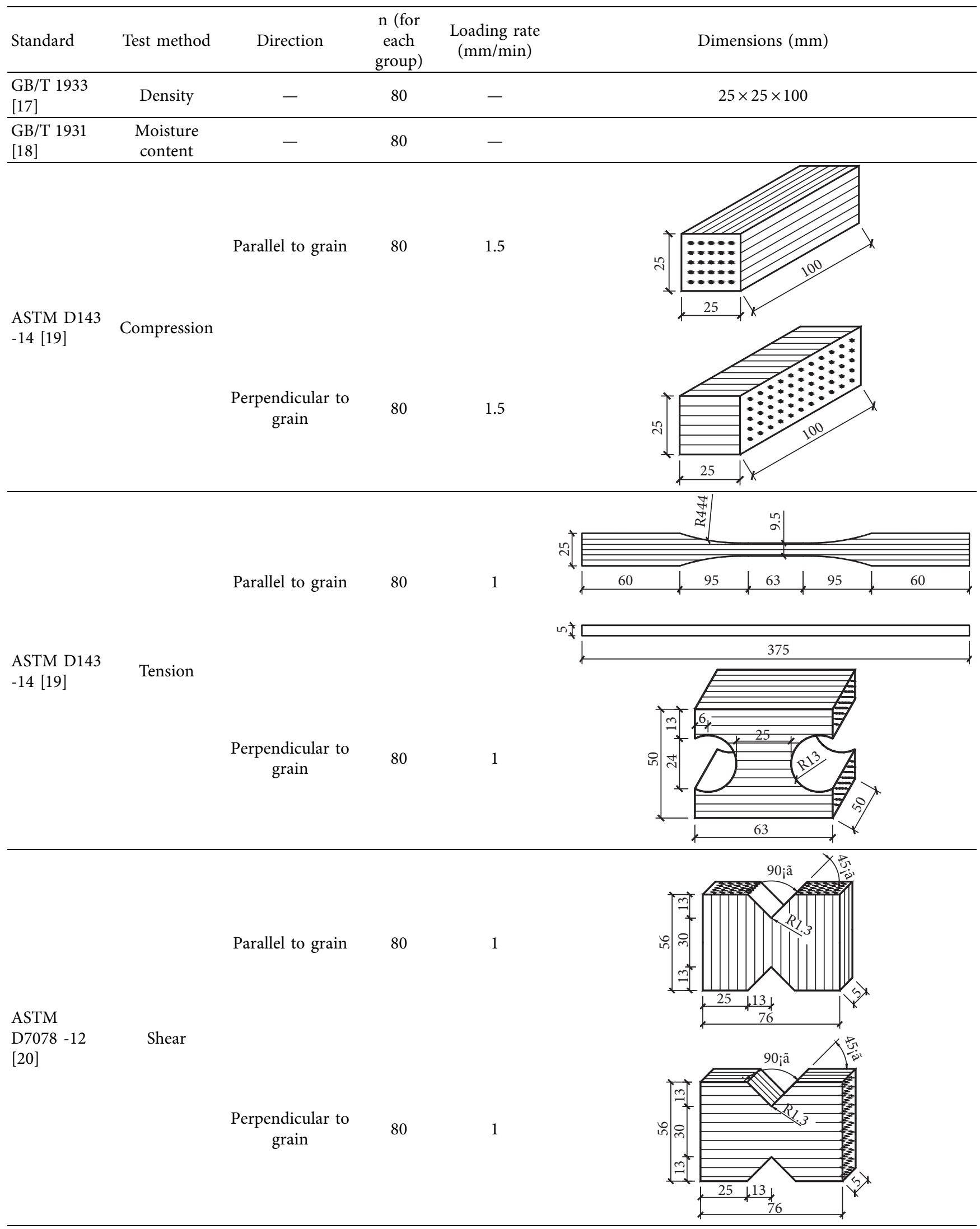


mean of the lognormal distribution; $\sigma_{\text {In }}$ is the standard deviation of the lognormal distribution; $K_{\text {In }}$ is the confidence level factor of the lognormal distribution; $\bar{X}$ is the mean of the Weibull distribution; $S$ is the standard deviation of the Weibull distribution; and $K_{W}$ is the confidence level factor of the Weibull distribution.

The EBC strength grading was conducted using a confidence band approach as described by Bahtiar et al. [16]. Statistical analysis was developed using correlation and linear regression. The parameters that had a strong correlation with strength will be considered potential predictors for EBC strength grading. Based on the confidence band in regression analysis, class intervals are created in similar ranges. According to the confidence band method, the 5th percentile lower value $\left(R_{0.05}\right)$ was calculated using equation (9). Then, the adaptation is applied by substituting the standard deviation $\left(S_{\mathrm{D}}\right)$ value with standard error for estimation in regression $\left(S_{\mathrm{E}}\right)$ (equation $(10)$ ). Finally, the characteristic value for each class $\left(R_{\mathrm{k}}\right)$ was obtained with equation (11).

$$
\begin{aligned}
R_{0.05} & =\hat{y}-t_{(v, 0.95)}\left(1+\frac{1}{n}+\frac{(x-\bar{x})^{2}}{\sum(x-\bar{x})^{2}}\right)^{0.5} S_{r} \\
S_{E} & =\left(1+\frac{1}{n}+\frac{(x-\bar{x})^{2}}{\sum(x-\bar{x})^{2}}\right)^{0.5} S_{r} \\
R_{k} & =R_{0.05}\left(1-\frac{k_{0.05,0.75} S_{E}}{m \sqrt{n}}\right)^{0.5},
\end{aligned}
$$

where $m$ is the average of strength from the test data; $n$ is the sample size; $\bar{x}$ is the mean of predictor value; $\hat{y}$ is the estimated strength when the predictor has $x$ value; $S_{r}$ is the standard error of regression; $S_{E}$ is the standard error of prediction at a given value of $x ; t_{(v, 0.95)}$ is the one-tailed Student's t-distribution value with $v$ degree of freedom for $95 \%$ probability; and $k_{0.05,0.75}$ is the confidence level factor for $75 \%$ confidence and $5 \%$ probability, which is interpolated from confidence level factor table in ASTM 2915 [12].

\section{Results and Discussion}

3.1. Mechanical Properties. A summary of the mechanical property test results according to the procedure defined in standards is presented in Table 3. The test results are assembled in Figure 4 which shows column plots for mechanical properties. The average value is indicated with a vertical column, and a vertical black whisker denotes the width of the standard deviation.

It is shown that the moisture content of EBC ranges from $5.3 \%$ to $9.18 \%$. There is a slight difference between PSB and LVB. However, the air-dry density of PSB is $0.98-1.31 \mathrm{~g} / \mathrm{cm}^{3}$, and LVB is $0.65-0.70 \mathrm{~g} / \mathrm{cm}^{3}$, respectively. Because of differences in manufacturing processes, adhesive content, and elements, PSB density is greater than LVB, which is closer to the density of raw bamboo.

In general, the mechanical behaviors of PSB and LVB are corresponding both parallel and perpendicular to the grain.
However, the PSB groups are superior to that of LVB in mechanical properties except for EBC4, which has the lowest density $\left(9.8 \mathrm{~g} / \mathrm{cm}^{3}\right)$ of PSB. This is a rare and unexpected result. It is considered that this tendency is given by the fibers within the phenol formaldehyde resin which are not dense enough, leading to more imperfections. Because the tensile strength of EBC is mainly determined by the bamboo fiber, the tensile strength in parallel to the grain of PSB and LVB is extremely close to the tensile strength of bamboo. With the exception of EBC4, the compressive strength of PSB is in the range of $99.29-119.04 \mathrm{MPa}$, which is significantly higher than that of LVB in the range of 55.93-69.22 MPa.

To compare the variability in mechanical properties, the coefficient of variations $(\mathrm{CV})$ are examined to the test results. Lower CV values suggest a smaller expected scattering in the corresponding variable. The compressive behavior in perpendicular to the grain shows the highest variability for all mechanical properties. It can be attributed to the inhomogeneity of the formaldehyde resin layer geometry, which leads to a nonhomogeneous fiber volume fraction over the sample volume. The group of EBC4 shows great variability in most tests for mechanical properties. It can be inferred that the density of PSB has a certain correlation with the strength parallel to the grain. Once the PSB density is less than the critical value, the mechanical properties will be significantly reduced, even lower than that of the $L V B$, whose density is smaller than that of PSB. Therefore, in the PSB manufacturing process, it is necessary to find and exceed the critical density, which makes the material manufacturing more homogeneous to reduce the nonhomogeneous fiber volume fraction.

3.2. Probability Distribution. In order to characterize the statistical distributions of mechanical properties for EBC, the test data are fitted to normal, lognormal, and Weibull models, and the goodness of fit analysis is conducted. Figure 5 shows the details of the best-fit distribution for the tension strength parallel to the grain of EBC5 as an example of the choice of distribution model. $\mathrm{H}$ indicates null hypothesis, and $\mathrm{P}$ is the probability of observing a test statistic as extreme as, or more extreme than, the observed value under the null hypothesis. $D$ is computed from the largest difference (in absolute value) between the observed and theoretical cumulative distribution functions in the figure. The details of the best-fit probability distribution functions of mechanical properties are shown in Table 4 and Table 5. For most groups of EBC, the normal distribution best-fitted the tensile strength parallel to the grain and shear strength perpendicular to the grain and compressive properties, the Weibull model presented the best fit for both shear strength parallel to the grain and tensile strength perpendicular to the grain, and the lognormal distribution best-fitted the tensile and shear modulus, which is inconsistent with research studies on other composite materials [22]. Table 6 shows the recommended best-fit distribution functions of the mechanical properties for EBC. 
TABLE 3: Summary of experimental results and characteristic values for EBC.

\begin{tabular}{|c|c|c|c|c|c|c|c|c|c|}
\hline & EBC1 & EBC2 & EBC3 & EBC4 & EBC5 & EBC6 & EBC7 & EBC8 & EBC9 \\
\hline$\rho\left(\mathrm{g} / \mathrm{cm}^{3}\right)$ & $1.31(0.04)$ & $1.31(0.06)$ & $1.23(0.06)$ & $0.98(0.06)$ & $1.14(0.05)$ & $0.68(0.04)$ & $0.65(0.04)$ & $0.67(0.02)$ & $0.70(0.05)$ \\
\hline$M c_{\text {mean }}(\%)$ & $5.30(0.04)$ & $5.75(0.07)$ & $7.56(0.06)$ & $7.26(0.05)$ & $9.18(0.06)$ & $8.38(0.04)$ & $7.52(0.03)$ & $7.59(0.04)$ & $7.07(0.06)$ \\
\hline \multicolumn{10}{|l|}{ Compression } \\
\hline$f_{c, 0, \text { mean }}(\mathrm{MPa})$ & $\begin{array}{l}112.89 \\
(0.08)\end{array}$ & $\begin{array}{l}119.04 \\
(0.08)\end{array}$ & $99.29(0.04)$ & $\begin{array}{l}66.72 \\
(0.11)\end{array}$ & $\begin{array}{l}101.95 \\
(0.06)\end{array}$ & $59.44(0.07)$ & $55.93(0.09)$ & $59.36(0.08)$ & $69.22(0.06)$ \\
\hline $\begin{array}{l}f_{c, 90, \text { mean }} \\
(\mathrm{MPa})\end{array}$ & $46.15(0.11)$ & $51.19(0.18)$ & $47.64(0.12)$ & $\begin{array}{l}27.09 \\
(0.19)\end{array}$ & $35.54(0.20)$ & $15.1(0.21)$ & $16.08(0.12)$ & $15.24(0.13)$ & $16.37(0.08)$ \\
\hline$f_{c, 0, k}(\mathrm{MPa})$ & 97.66 & 102.73 & 91.49 & 53.44 & 90.24 & 51.79 & 46.94 & 50.94 & 61.50 \\
\hline$f_{c, 90, k}(\mathrm{MPa})$ & 46.15 & 51.19 & & 18.13 & 35.54 & & & & 16.37 \\
\hline$E_{c, 0, \text { mean }}(\mathrm{GPa})$ & $19.48(0.08)$ & $17.43(0.10)$ & $15.37(0.05)$ & $\begin{array}{l}12.52 \\
(0.10)\end{array}$ & $16.82(0.10)$ & $13.03(0.07)$ & $10.45(0.09)$ & $11.61(0.08)$ & $12.87(0.06)$ \\
\hline $\begin{array}{l}E_{c, 90, \text { mean }} \\
(\mathrm{GPa})\end{array}$ & $4.04(0.16)$ & $4.53(0.20)$ & $3.88(0.10)$ & $2.77(0.16)$ & $3.44(0.12)$ & $1.87(0.23)$ & $1.87(0.13)$ & $2.19(0.22)$ & $2.01(0.10)$ \\
\hline \multicolumn{10}{|l|}{ Tension } \\
\hline$f_{t, 0, \text { mean }}(\mathrm{MPa})$ & $\begin{array}{l}141.73 \\
(0.24)\end{array}$ & $\begin{array}{l}130.60 \\
(0.20)\end{array}$ & $\begin{array}{r}133.19 \\
(0.13)\end{array}$ & $\begin{array}{l}99.91 \\
(0.33)\end{array}$ & $\begin{array}{l}125.86 \\
(0.20)\end{array}$ & $\begin{array}{l}127.71 \\
(0.10)\end{array}$ & $\begin{array}{l}124.25 \\
(0.24)\end{array}$ & $\begin{array}{l}103.71 \\
(0.18)\end{array}$ & $\begin{array}{l}117.05 \\
(0.19)\end{array}$ \\
\hline $\begin{array}{l}f_{t, 90, \text { mean }} \\
(\mathrm{MPa})\end{array}$ & $5.2(0.22)$ & $7.29(0.15)$ & $9.38(0.21)$ & $2.52(0.31)$ & $3.14(0.34)$ & $4.30(0.18)$ & $5.03(0.11)$ & $5.45(0.31)$ & $6.79(0.18)$ \\
\hline$f_{t, 0, k}(\mathrm{MPa})$ & 81.15 & 83.86 & 103.55 & 39.89 & 81.06 & 89.89 & 71.38 & 70.05 & 80.38 \\
\hline$f_{t, 90, k}(\mathrm{MPa})$ & 3.15 & 5.59 & 5.85 & 1.17 & 1.11 & 2.84 & 3.92 & 2.37 & 4.46 \\
\hline$E_{t, 0, \text { mean }}(\mathrm{GPa})$ & $19.11(0.10)$ & $16.58(0.12)$ & $14.48(0.09)$ & $\begin{array}{l}14.02 \\
(0.22)\end{array}$ & $16.96(0.15)$ & $13.19(0.13)$ & $12.82(0.22)$ & $9.82(0.17)$ & $11.56(0.16)$ \\
\hline $\begin{array}{l}E_{t, 90, \text { mean }} \\
(\mathrm{GPa})\end{array}$ & $3.22(0.26)$ & $8.98(0.26)$ & $7.09(0.25)$ & $1.06(0.22)$ & $1.44(0.25)$ & $3.7(0.24)$ & $8.43(0.26)$ & $3.74(0.25)$ & $6.51(0.26)$ \\
\hline \multicolumn{10}{|l|}{ Shear } \\
\hline$f_{s, 0, \text { mean }}(\mathrm{MPa})$ & $19.9(0.19)$ & $16.15(0.24)$ & $18.79(0.16)$ & $9.01(0.29)$ & $10.69(0.26)$ & $15.44(0.17)$ & $10.36(0.28)$ & $14.6(0.17)$ & $11.89(0.20)$ \\
\hline $\begin{array}{l}f_{s, 90, \text { mean }} \\
(\mathrm{MPa})\end{array}$ & $26.11(0.23)$ & $40.35(0.15)$ & $34.45(0.12)$ & $\begin{array}{l}20.77 \\
(0.16)\end{array}$ & $32.63(0.15)$ & $18.49(0.12)$ & $21.68(0.17)$ & $17.87(0.13)$ & $12.83(0.20)$ \\
\hline$f_{s, 0, k}(\mathrm{MPa})$ & 12.77 & 8.88 & & 4.05 & 5.19 & 10.75 & 4.89 & 9.69 & 8.16 \\
\hline$f_{s, 90, k}(\mathrm{MPa})$ & 15.44 & 29.48 & & 14.44 & 23.92 & 14.63 & 15.17 & 13.68 & 8.24 \\
\hline$G_{s, 0, \text { mean }}(\mathrm{GPa})$ & $5.13(0.13)$ & $4.22(0.12)$ & $4.45(0.10)$ & $2.17(0.15)$ & $3.80(0.10)$ & $2.62(0.14)$ & $2.35(0.15)$ & $2.95(0.11)$ & $2.58(0.10)$ \\
\hline $\begin{array}{l}G_{s, 90, \text { mean }} \\
(\mathrm{GPa})\end{array}$ & $5.8(0.12)$ & $5.03(0.15)$ & $4.62(0.16)$ & $2.77(0.17)$ & $4.45(0.12)$ & $2.99(0.13)$ & $2.86(0.17)$ & $3.06(0.15)$ & $2.54(0.09)$ \\
\hline
\end{tabular}

Note. The coefficient of variation is shown in parentheses.

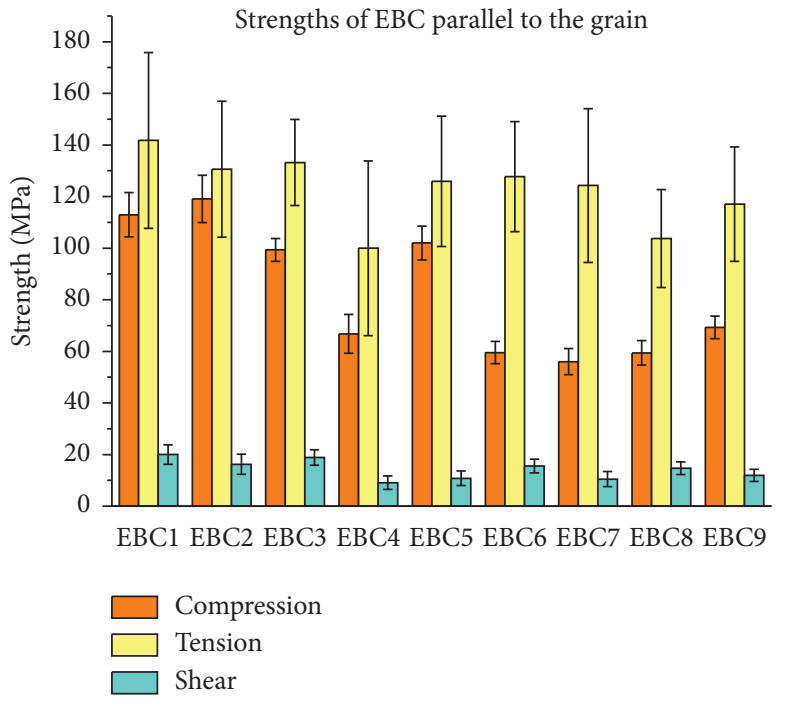

(a)

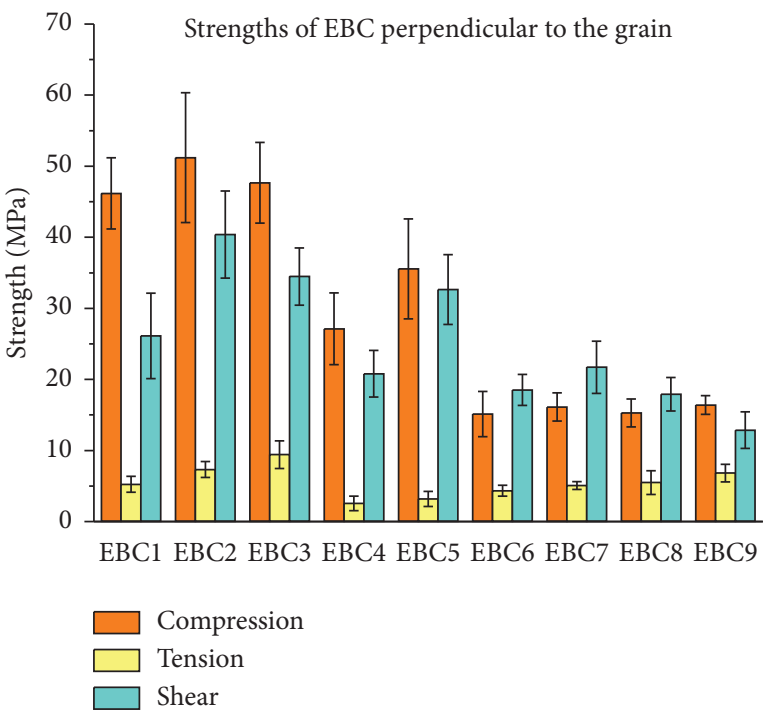

(b)

FIgUre 4: Continued. 


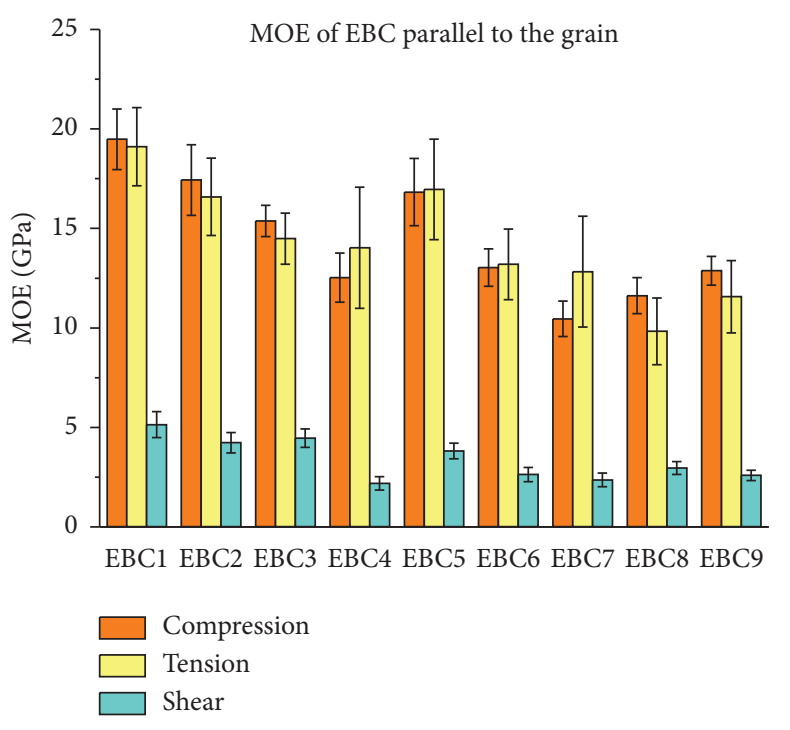

(c)

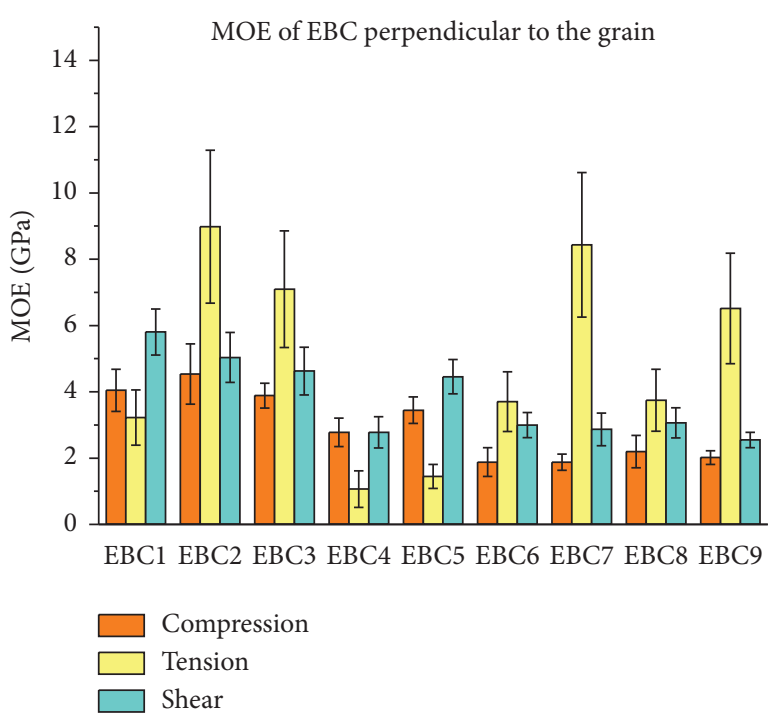

(d)

Figure 4: Strengths and moduli distributions of experimental data: strengths in parallel to the grain (a); strengths in perpendicular to the grain (b); moduli in parallel to the grain (c); moduli in perpendicular to the grain (d).

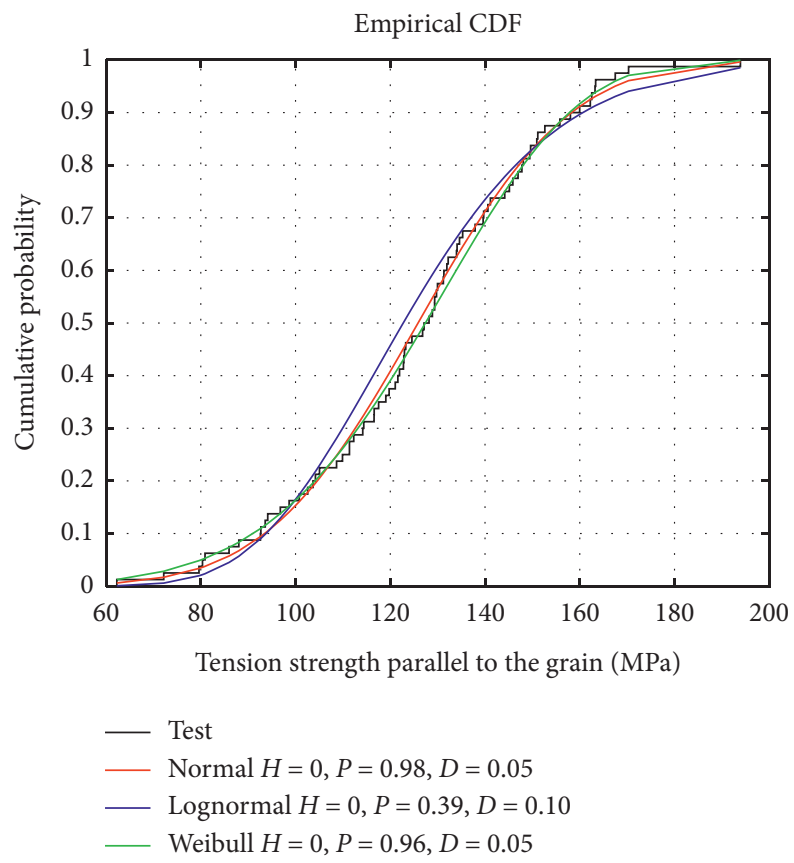

Figure 5: Example of the Kolmogorov-Smirnov tests for the goodness of fit analysis.

3.3. Strength Grading of EBC. The objective of this section was to develop the strength grading of EBC, which is expected that the results can be applied in structural design. The first step is to determine the potential predictors with a stronger correlation with compressive strength through correlation analysis, which was chosen as IPs. Density and MOE frequently show a strong correlation with strength properties of European hardwoods [23-25]. For this work, density and compressive modulus were chosen as potential predictors for compressive strength. To verify potential predictors, a simple linear regression was conducted between predictors ( $\rho$ and $E_{c, 0}$ ) and response $\left(f_{c, 0}\right)$. According to the linear regression, the correlation coefficient between $\rho$ and $f_{c, 0}$ was in the range of $0.58-0.79$, and between $E_{c, 0}$ and $f_{c, 0}$, it was 0.58-0.79 (Table 7). Hence the density and compressive MOE were selected as IPs for strength grading.

In this research, EBC grading based on compressive strength was established by the confidence band. The outlier and extreme values were justified and removed from further analysis by utilizing a $99 \%$ ellipse band and $95 \%$ predicted 
TABLE 4: The details of the best-fit distribution functions of modulus for EBC.

\begin{tabular}{|c|c|c|c|c|c|c|}
\hline \multirow{2}{*}{ Group } & \multicolumn{2}{|c|}{ Compression } & \multicolumn{2}{|c|}{ Tension } & \multicolumn{2}{|c|}{ Shear } \\
\hline & $E_{c, 0}$ & $E_{c, 90}$ & $E_{t, 0}$ & $E_{t, 90}$ & $G_{s, 0}$ & $G_{s, 90}$ \\
\hline EBC1 & $-L\left(2.97,0.08^{2}\right)$ & $x-N\left(4.04,0.64^{2}\right)$ & $x-L\left(2.94,0.10^{2}\right)$ & $x-N\left(3.22,0.84^{2}\right)$ & $x-L\left(1.63,0.13^{2}\right)$ & $\left.x-L 1.49,0.12^{2}\right)$ \\
\hline EBC2 & $x-N\left(17.39,1.80^{2}\right)$ & $x-L\left(1.49,0.19^{2}\right)$ & $-L\left(2.80,0.12^{2}\right)$ & $x-L\left(2.16,0.26^{2}\right)$ & $x-L\left(1.43,0.12^{2}\right)$ & $x-L\left(1.60,0.15^{2}\right)$ \\
\hline & $x-L\left(2.73,0.05^{2}\right)$ & $x-L\left(1.35,0.10^{2}\right)$ & $x-L\left(2.67,0.09^{2}\right)$ & $x-L\left(1.93,0.25^{2}\right)$ & $x-W(4.64,9.86)$ & $x-W(4.92,7.53)$ \\
\hline $3 C_{4}$ & $x-N\left(9.43,0.10^{2}\right)$ & $x-N\left(2.77,0.43^{2}\right)$ & $x-L\left(2.62,0.22^{2}\right)$ & $x-W(1.25,3.36)$ & $x-L\left(0.77,0.17^{2}\right)$ & $x-L\left(1.01,0.16^{2}\right)$ \\
\hline EBC5 & $x-N\left(16.82,1.69^{2}\right)$ & $x-N\left(3.44,0.40^{2}\right)$ & $x-N\left(16.96,2.53^{2}\right)$ & $x-W(1.58,4.56)$ & $x-L\left(1.43,0.12^{2}\right)$ & $\left.x-L 1.49,0.12^{2}\right)$ \\
\hline EBC6 & $x-N\left(13.03,0.94^{2}\right)$ & $x-W(2.05,4.82)$ & $x-N\left(13.19,1.77^{2}\right)$ & $x-L\left(1.28,0.25^{2}\right)$ & $x-N\left(2.62,0.35^{2}\right)$ & $x-N\left(2.54,0.23^{2}\right)$ \\
\hline & $x-N\left(10.45,0.89^{2}\right)$ & $x-N\left(1.88,0.24^{2}\right)$ & $x-L\left(2.53,0.22^{2}\right)$ & $x-W(9.26,4.39)$ & $x-L\left(0.85,0.14^{2}\right)$ & $x-N\left(2.99,0.38^{2}\right)$ \\
\hline & $x-L\left(2.45,0.08^{2}\right)$ & $x-W(2.38,5.10)$ & $x-L\left(2.27,0.17^{2}\right)$ & $x-L\left(1.84,0.26^{2}\right)$ & $x-N\left(2.95,0.32^{2}\right)$ & $x-W(3.07,5.95)$ \\
\hline EBC9 & $x-L\left(2.55,0.06^{2}\right)$ & $x-N\left(2.01,0.20^{2}\right)$ & $x-N\left(11.56,1.82^{2}\right)$ & $x-L\left(1.29,0.25^{2}\right)$ & $x-L\left(0.94,0.10^{2}\right)$ & $x-L\left(1.11,0.15^{2}\right)$ \\
\hline
\end{tabular}

TABLE 5: The details of the best-fit distribution functions of strengths for EBC.

\begin{tabular}{|c|c|c|c|c|c|c|}
\hline \multirow{2}{*}{ Group } & \multicolumn{2}{|c|}{ Compression } & \multicolumn{2}{|c|}{ Tension } & \multicolumn{2}{|c|}{ Shear } \\
\hline & $f_{c, 0}$ & $f_{c, 90}$ & $f_{t, 0}$ & $f_{t, 90}$ & $f_{s, 0}$ & $f_{s, 90}$ \\
\hline $\mathrm{EBC} 1$ & $x-N\left(112.89,8.57^{2}\right)$ & $x-N\left(46.15,5.02^{2}\right)$ & $x-N\left(141.73,34.09^{2}\right)$ & $x-W(5.63,5.62)$ & $x-W(24.41,6.23)$ & $x-N\left(26.11,6.02^{2}\right)$ \\
\hline $\mathrm{EBC} 2$ & $x-N\left(119.04,9.20^{2}\right)$ & $x-N\left(51.19,9.13^{2}\right)$ & $x-N\left(130.60,26.35^{2}\right)$ & $x-L\left(1.98,0.15^{2}\right)$ & $x-W(17.64,4.85)$ & $x-N\left(40.35,6.13^{2}\right)$ \\
\hline EBC3 & $x-N\left(99.29,4.40^{2}\right)$ & $x-N\left(47.64,5.68^{2}\right)$ & $x-N\left(133.19,16.72^{2}\right)$ & $x-W(10.13,5.88)$ & $x-W(20.09,6.77)$ & $x-N\left(34.45,4.04^{2}\right)$ \\
\hline EBC4 & $x-N\left(66.72,7.49^{2}\right)$ & $x-N\left(27.09,5.05^{2}\right)$ & $x-N\left(99.90,33.85^{2}\right)$ & $x-N\left(2.66,0.84^{2}\right)$ & $x-L\left(2.16,0.30^{2}\right)$ & $x-N\left(3.02,0.17^{2}\right)$ \\
\hline EBC5 & $x-N\left(101.95,6.59^{2}\right)$ & $x-N\left(35.54,7.04^{2}\right)$ & $x-N\left(125.86,25.27^{2}\right)$ & $x-W(3.51,3.23)$ & $x-W(11.75,4.20)$ & $x-W(34.65,8.10)$ \\
\hline EBC6 & $x-N\left(59.44,4.30^{2}\right)$ & $x-N\left(15.10,3.18^{2}\right)$ & $x-N\left(127.71,21.33^{2}\right)$ & $x-W(4.61,6.60)$ & $x-W(16.51,7.38)$ & $x-N\left(18.49,2.18^{2}\right)$ \\
\hline EBC7 & $x-N\left(55.93,5.07^{2}\right)$ & $x-N\left(16.08,1.98^{2}\right)$ & $x-N\left(124.25,29.80^{2}\right)$ & $x-N\left(5.03,0.54^{2}\right)$ & $x-W(11.45,4.06)$ & $x-W(23.19,7.20)$ \\
\hline EBC8 & $x-N\left(59.36,4.75^{2}\right)$ & $x-N\left(15.24,1.97^{2}\right)$ & $x-N\left(103.71,18.97^{2}\right)$ & $x-W(6.04,3.77)$ & $x-W(15.60,6.71)$ & $x-N\left(17.87,2.36^{2}\right)$ \\
\hline EBC9 & $x-N\left(69.22,4.36^{2}\right)$ & $x-N\left(16.37,1.33^{2}\right)$ & $x-L\left(4.75,0.19^{2}\right)$ & $x-W(7.30,6.53)$ & $x-L\left(2.46,0.20^{2}\right)$ & $x-N\left(12.83,2.57^{2}\right)$ \\
\hline
\end{tabular}

TABle 6: The recommended best-fit distribution functions of the mechanical properties for EBC.

\begin{tabular}{lr}
\hline Property & Best-fit distribution \\
\hline$f_{c, 0}$ & Normal \\
$f_{c, 90}$ & Normal \\
$E_{c, 0}$ & Normal \\
$E_{c, 90}$ & Normal \\
$f_{t, 0}$ & Normal \\
$f_{t, 90}$ & 2 -P Weibull \\
$E_{t, 0}$ & Lognormal \\
$E_{t, 90}$ & Lognormal \\
$f_{s, 0}$ & 2-P Weibull \\
$f_{s, 90}$ & Normal \\
$G_{s, 0}$ & Lognormal \\
$G_{s, 90}$ & Lognormal \\
\hline
\end{tabular}

TABLE 7: Correlation coefficients $\left(R^{2}\right)$ between predictors and response for EBC.

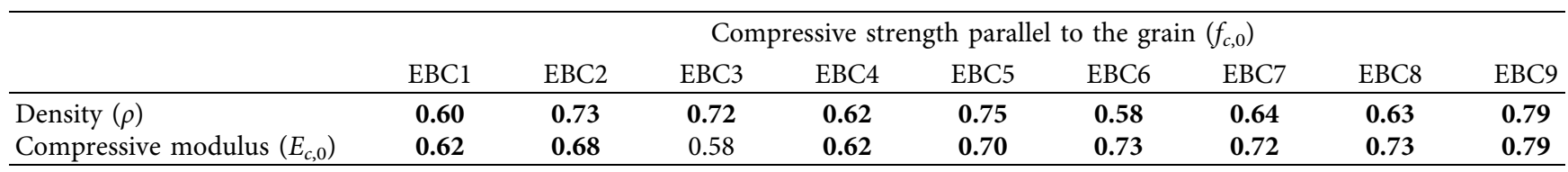

Note. The correlations significant at $p<0.05$ are displayed in bold.

band. The examples of ellipse confidence band analysis are shown in Figure 6.

Density and MOE were IPs for strength grading for EBC since they were strong correlation with compressive strength. Using the confidence band approach to perform regression analysis on the EBC for strength grading, $R^{2}$ is sufficiently high in the range of 0.44 to 0.87 . Figure 7 shows the confidence bands used to develop the EBC strength grading. The confidence band method generates a continuous function, and the stair function can be used to 


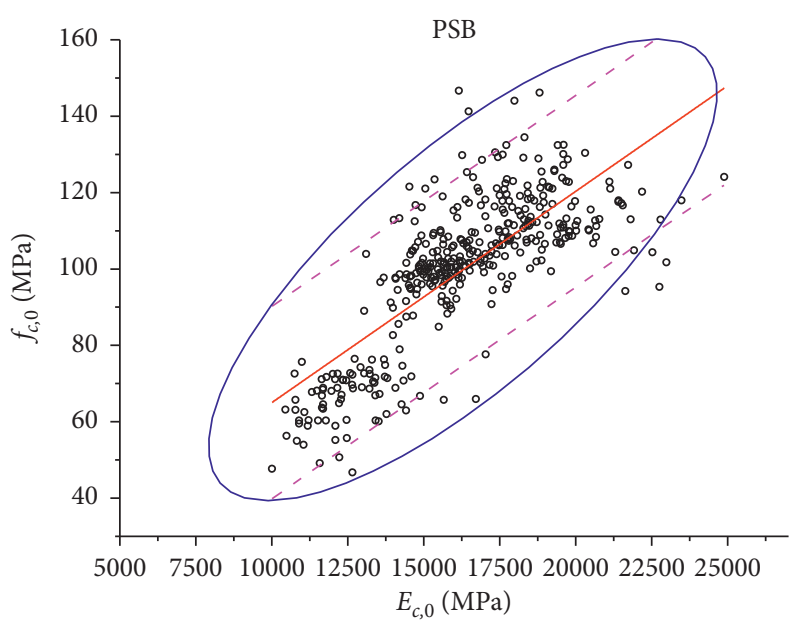

(a)

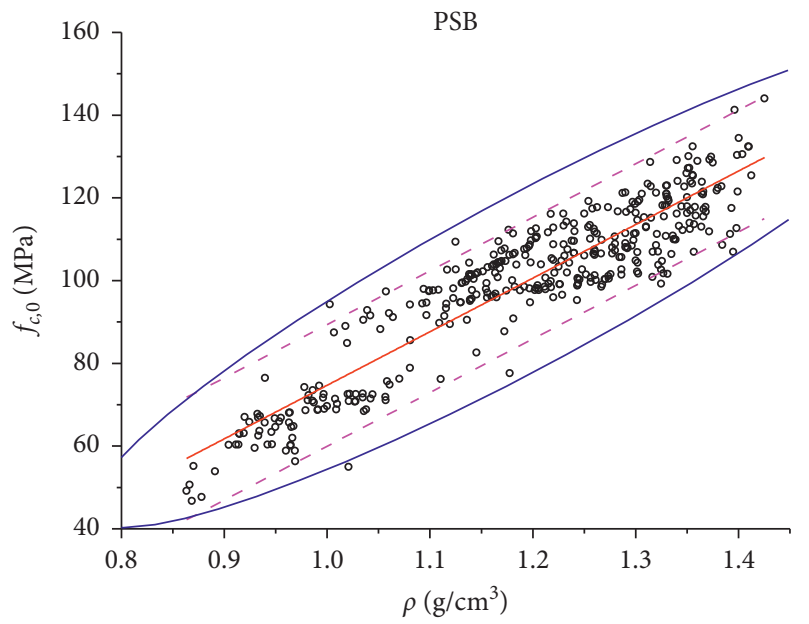

(c)

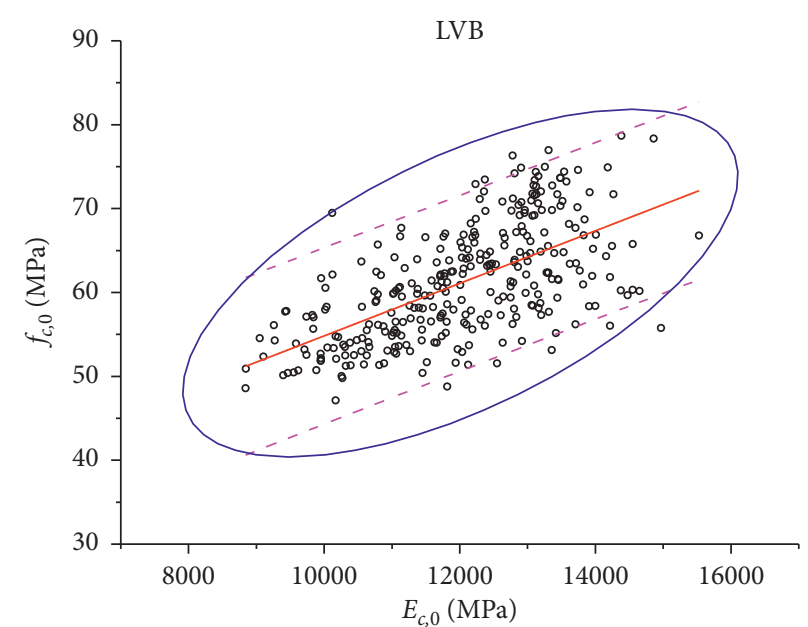

(b)

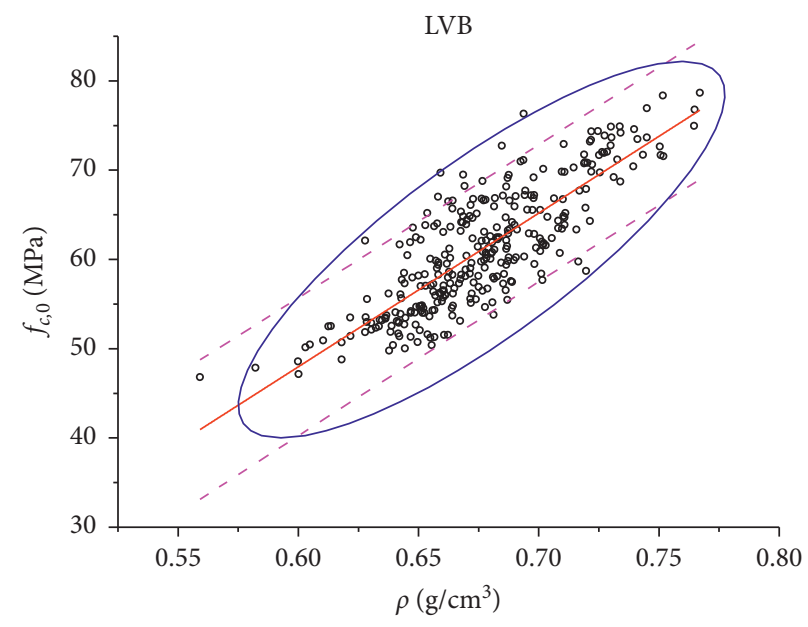

(d)

FIGURE 6: Ellipse band and predicted band analysis of linear regression: $f_{c, 0}$ against $E_{c, 0}$ for PSB (a); $f_{c, 0}$ against $E_{c, 0}$ for LVB (b); $f_{c, 0}$ against $\rho$ for PSB (c); $f_{c, 0}$ against $\rho$ for LVB (d).
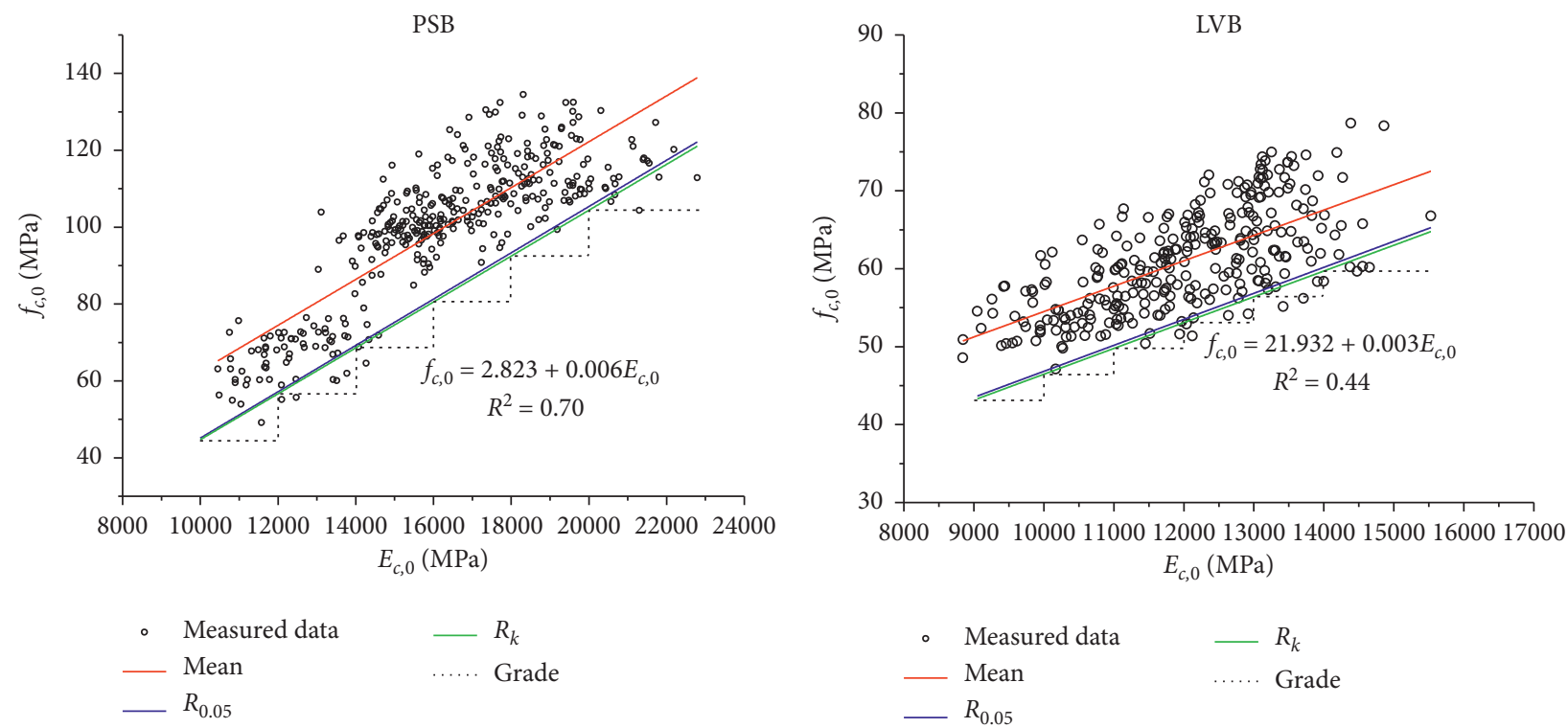

(a)

(b)

Figure 7: Continued. 


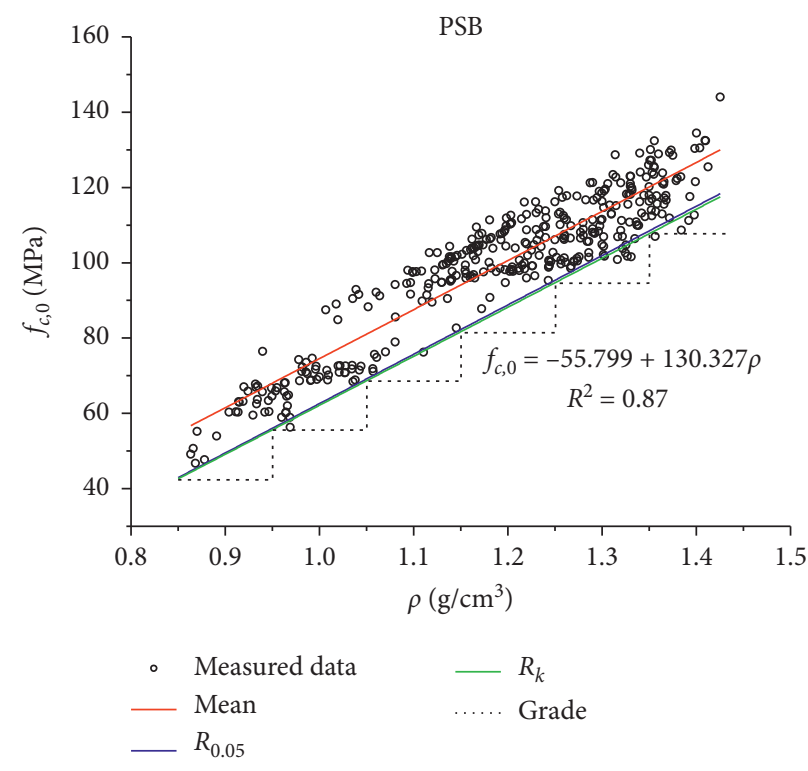

(c)

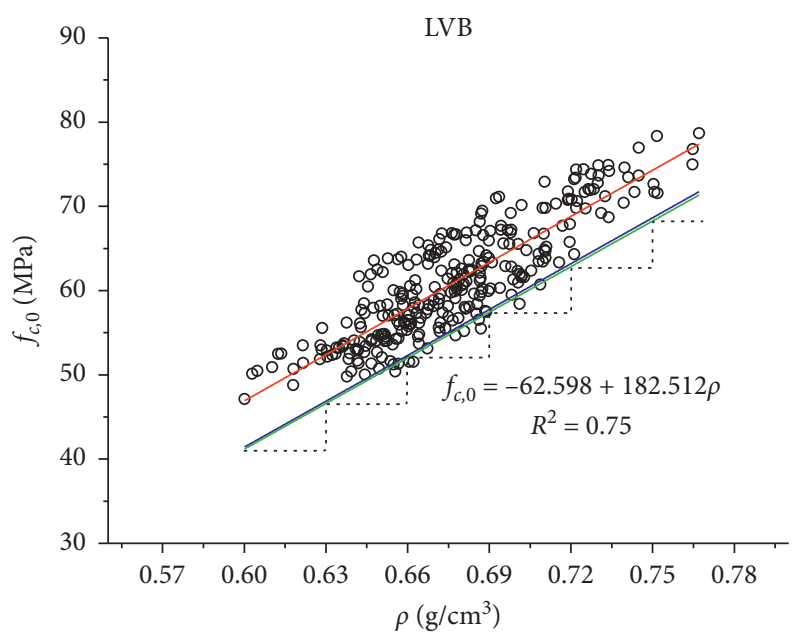

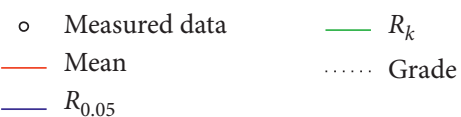

(d)

FIGURE 7: Compressive strength grading of EBC: based on compressive modulus for PSB (a); based on compressive modulus for LVB (b); based on density for PSB (c); based on density for LVB (d).

TABLE 8: Compressive strength grade classification of EBC based on compressive modulus.

\begin{tabular}{lcrr}
\hline $\begin{array}{l}\text { Grade }\left(E_{c, 0}\right) \\
\text { Interval }(\mathrm{MPa})\end{array}$ & Mean & Compressive strength $\left(f_{c, 0}, \mathrm{MPa}\right)$ & $R_{0.05}$ \\
\hline PSB & & & $R_{k}$ \\
$10000-11999$ & 63.10 & 51.12 & 50.70 \\
$12000-13999$ & 72.58 & 63.16 & 62.64 \\
$14000-15999$ & 98.13 & 75.20 & 74.58 \\
$16000-17999$ & 108.71 & 87.24 & 86.52 \\
$18000-19999$ & 115.16 & 99.28 & 98.46 \\
$\geq 20000$ & 116.07 & 111.32 & 110.40 \\
\hline LVB & & & \\
$9000-9999$ & 54.00 & 45.21 & \\
$10000-10999$ & 55.41 & 48.55 & \\
$11000-11999$ & 58.74 & 51.89 & 44.80 \\
$12000-12999$ & 63.08 & 55.23 & 51.42 \\
$13000-13999$ & 66.45 & 58.57 & 511 \\
$\geq 14000$ & 67.22 & 61.91 & 58.04 \\
\hline
\end{tabular}

TABLE 9: Compressive strength grade classification of EBC based on density.

\begin{tabular}{lccc}
\hline Grade $(\rho)$ & & Compressive strength $\left(f_{c, 0,} \mathrm{MPa}\right)$ & $R_{0.05}$ \\
Interval $\left(\mathrm{g} / \mathrm{cm}^{3}\right)$ & Mean & & \\
\hline PSB & & 49.47 & 49.12 \\
$0.85-0.949$ & 61.17 & 62.58 & 62.14 \\
$0.95-1.049$ & 71.24 & 75.69 & 75.16 \\
$1.05-1.149$ & 87.58 & 88.80 & 88.18 \\
$1.15-1.249$ & 101.93 & 101.92 & 101.20 \\
$1.25-1.349$ & 111.45 & 115.03 & 114.22 \\
$\geq 1.35$ & 121.94 & & \\
LVB & & 44.14 & \\
$0.60-0.629$ & 51.57 & 49.58 & 43.89 \\
$0.63-0.659$ & 55.43 & 55.03 & 49.31 \\
$0.66-0.689$ & 60.48 & 60.48 & 54.72 \\
$0.69-0.719$ & 65.45 & 65.92 & 60.14 \\
$0.72-0.749$ & 72.23 & 71.37 & 65.56 \\
$\geq 0.750$ & 74.95 & & 70.97 \\
\hline
\end{tabular}


subdivide the function into several grades at the specified interval of IP. Each grade had $R_{0.05}$ and $R_{k}$ of $f_{c, 0}$, which could be utilized in EBC structural design following a strength-based approach. Table 8 and Table 9 show the grading of PSB and LVB into strength grades based on density and MOE. The higher quality grades have higher strength. The designer can estimate the characteristic value of compressive strength based on the IPs according to Table 8 and Table 9 for modern engineered bamboo structural design.

\section{Conclusions}

This study statistically investigates the mechanical properties of two types of EBC for seven manufacturers with raw materials from five regions in China. To study the mechanical behaviors of groups for $\mathrm{EBC}$, tensile, compressive, and shear tests were carried out on small clear specimens. The study utilized wood standards for characterization, determining the probability distributions and characteristic values for mechanical properties. Except for the PSB with lower density, the mechanical properties of PSB are generally higher than those of LVB.

In addition, the statistical parameters of the best-fit probability distribution models for mechanical properties can be utilized to determine the characteristic values and build the probabilistic design approach. The results are conducive to developing design standards and reliability evaluation practices for EBC structures and extending the particular applications in engineering.

Due to their more significant correlation coefficients, density and compressive modulus were considered the most suitable IPs for strength grading of EBC subject to compressive strength. According to the confidence band method, grade intervals are built in similar ranges, and the characteristic value in each grade can be calculated.

After comparing the results from different sources, it is found that although the results obtained from the test are similar, there is significant variation in the differences between different sources of the same material. The research shows that future work needs to determine the source of variation in testing and establish a complete reliability analysis and strength grading.

\section{Nomenclature}

$E_{c, 0}$ : $\quad$ Compressive modulus parallel to the grain

$E_{c, 0 \text {,mean }}$ Mean compressive parallel to the grain

$f_{s, 0}: \quad$ Shear strength parallel to the grain

$f_{s, 0, k}$ : Characteristic shear strength parallel to the grain

$E_{c, 90}: \quad$ Compressive modulus parallel perpendicular to the grain

$E_{c, 90, \text { mean: }}$ Mean compressive modulus parallel perpendicular to the grain

$f_{s, 90}$ : $\quad$ Shear strength perpendicular to the grain

$f_{s,}, 90, k$ Characteristic shear strength perpendicular to

$E_{t, 0}: \quad$ the grain $\quad$ Tensile modulus parallel to the grain
$E_{t, 0 \text {, mean }} \quad$ Mean tensile modulus parallel to the grain

$G_{s, 0}$ : Shear modulus parallel to the grain

$G_{s, 0}$, mean: Mean shear modulus parallel to the grain

$E_{t, 90}$ : Tensile modulus perpendicular to the grain

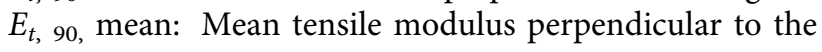
grain

$G_{s, 90}: \quad$ Shear modulus perpendicular to the grain

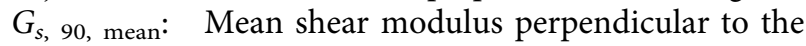
grain

$f_{c, 0}: \quad$ Compressive strength parallel to the grain

$f_{c, 0, k}$ Characteristic compressive strength parallel to the grain

Mc: $\quad$ Moisture content

$\mathrm{Mc}_{\text {mean }}$ : Mean moisture content

$f_{c, 90}: \quad$ Compressive strength perpendicular to the

$f_{c, 90, k}: \quad$ Characteristic compressive strength

perpendicular to the grain

$\rho: \quad$ Mean air-dry density

MOE: $\quad$ Modulus of elastic

$f_{t, 0}$ : Tensile strength parallel to the grain

$f_{t, 0, k}: \quad$ Characteristic tensile strength parallel to the

$f_{t, 90}: \quad$ Tensile strength perpendicular to the grain

$f_{t}, 90, k: \quad$ Characteristic tensile strength perpendicular to the grain.

\section{Data Availability}

The data used to support the findings of this study are available from the corresponding author upon request.

\section{Conflicts of Interest}

The authors declare that they have no conflicts of interest.

\section{Acknowledgments}

This research was supported by the National Natural Science Foundation of China (no. 51978338), Basic Ability Improvement Program of Young and Middle-Aged Scholar for the Education Office of Guangxi Province (no. 2019KY0236) and Priority Academic Program Development of Jiangsu Higher Education Institutions (PAPD).

\section{References}

[1] Y. Xiao, R. Z. Yang, and B. Shan, "Corrigendum to "Production, environmental impact and mechanical properties of glubam"' Construction and Building Materials, vol. 44, p. 805, 2013.

[2] P. J. Shi, "Precipitation is the most crucial factor determining the distribution of moso bamboo in Mainland China," Global Ecology and Conservation, vol. 22, 2020.

[3] S. Amada and S. Untao, "Fracture properties of bamboo," Composites Part B-Engineering, vol. 32, no. 5, pp. 449-457, 2001.

[4] F. Wang, Z. Shao, and Y. Wu, "Mode II interlaminar fracture properties of Moso bamboo," Composites Part B: Engineering, vol. 44, no. 1, pp. 242-247, 2013. 
[5] D. S. Huang, A. P. Zhou, and Y. L. Bian, "Experimental and analytical study on the nonlinear bending of parallel strand bamboo beams," Construction and Building Materials, vol. 44, pp. 585-592, 2013.

[6] D. Huang, Y. Bian, A. Zhou, and B. Sheng, "Experimental study on stress-strain relationships and failure mechanisms of parallel strand bamboo made from phyllostachys," Construction and Building Materials, vol. 77, pp. 130-138, 2015.

[7] Y. Wei, "Stress-strain relationship model of glulam bamboo under axial loading," Advanced Composites Letters, vol. 29, 2020.

[8] Y. Xiao, Y. Wu, J. Li, and R. Z. Yang, "An experimental study on shear strength of glubam," Construction and Building Materials, vol. 150, pp. 490-500, 2017.

[9] B. Sharma, A. Gatóo, M. Bock, and M. Ramage, "Engineered bamboo for structural applications," Construction and Building Materials, vol. 81, pp. 66-73, 2015.

[10] A. Kumar, T. Vlach, L. Laiblova et al., "Engineered bamboo scrimber: influence of density on the mechanical and water absorption properties," Construction and Building Materials, vol. 127, pp. 815-827, 2016.

[11] B. S. Institution, Bs En 384 - Structural Timber - Determination of Characteristic Values of Mechanical Properties and Density, 2018.

[12] ASTM, Practice for Sampling and Data-Analysis for Structural Wood and Wood-Based Products, ASTM International West, Conshohocken, PA, USA, 2017.

[13] D. Trujillo, S. Jangra, and J. M. Gibson, "Flexural properties as a basis for bamboo strength grading," Proceedings of the Institution of Civil Engineers - Structures and Buildings, vol. 170, no. 4, pp. 284-294, 2017.

[14] N. N. Nurmadina, N. Nugroho, and E. T. Bahtiar, "Structural grading of Gigantochloa apus bamboo based on its flexural properties," Construction and Building Materials, vol. 157, pp. 1173-1189, 2017.

[15] E. T. Bahtiar, A. P. Imanullah, D. Hermawan, N. Nugroho, and fnm Abdurachman, "Structural grading of three sympodial bamboo culms (Hitam, Andong, and Tali) subjected to axial compressive load," Engineering Structures, vol. 181, pp. 233-245, 2019.

[16] E. T. Bahtiar, D. Trujillo, and N. Nugroho, "Compression resistance of short members as the basis for structural grading of Guadua angustifolia," Construction and Building Materials, vol. 249, 2020.

[17] China SAO, Method for Determination of the Density of Wood, GB/T 1933-2009, Macau, China, 2009.

[18] China SAO, Method for Determination of Moisture Content of Wood, GB/T 1931-2009, Macau, China, 2009.

[19] ASTM, Standard Test Methods for Small Clear Specimens of Timber, ASTM International West Conshohocken, Conshohocken, PA, USA, 2014.

[20] ASTM, Standard Test Method for Shear Properties of Composite Materials by V-Notched Rail Shear Method, ASTM International West Conshohocken, Conshohocken, PA, USA, 2012.

[21] B. P. Murphy, I. M. Chakravarti, R. G. Laha, and J. Roy, "Handbook of methods of applied statistics. Vol. I: techniques of computation, descriptive methods and statistical inference," Applied Statistics, vol. 17, no. 3, p. 293, 1968.

[22] J. P. Torres, L.-J. Vandi, M. Veidt, and M. T. Heitzmann, "The mechanical properties of natural fibre composite laminates: a statistical study," Composites Part A: Applied Science and Manufacturing, vol. 98, pp. 99-104, 2017.
[23] CEN, Structural Timber - Strength Classes. EN 338. 2016, European Committee for Standardisation, Brussels, Belgium.

[24] G. Riesco Muñoz, A. Remacha Gete, and F. Pedras Saavedra, "Implications in the design of a method for visual grading and mechanical testing of hardwood structural timber for designation within the European strength classes," Forest Systems, vol. 20, no. 2, pp. 235-244, 2011.

[25] A. Kovryga, P. Stapel, and J. W. G. van de Kuilen, "Mechanical properties and their interrelationships for medium-density European hardwoods, focusing on ash and beech," Wood Material Science \& Engineering, vol. 15, no. 5, pp. 289-302, 2020. 